\title{
Influence of preparation techniques of cellulose II nanocrystals as reinforcement for tannery solid waste-based gelatin composite films
}

\section{Vimudha Muralidharan}

CSIR-CLRI: Central Leather Research Institute CSIR

\section{Saiprasad Gochhayat}

BITS Hyderabad: Birla Institute of Technology \& Science Pilani - Hyderabad Campus

\section{Saravanan Palanivel}

CSIR-CLRI: Central Leather Research Institute CSIR

Balaraman Madhan ( $\nabla$ madhan@clri.res.in )

CSIR-CLRI: Central Leather Research Institute CSIR https://orcid.org/0000-0002-4198-8452

\section{Research Article}

Keywords: cellulose II nanocrystal, wet-wipes, leather waste, gelatin, biodegradable packaging

Posted Date: March 2nd, 2022

DOI: https://doi.org/10.21203/rs.3.rs-1360680/v1

License: (a) (i) This work is licensed under a Creative Commons Attribution 4.0 International License. Read Full License 


\section{Abstract}

Herein, the leather waste-based gelatin composite film reinforced with cellulose II nanocrystal (CNC II) extracted from wet wipes using three different hydrolysis techniques is explored for its functional properties. CNC II isolated using peroxide (PCNC), citric acid (CCNC) and hydrochloric acid (HCNC) differed in morphological and crystalline character as investigated using DLS, FE-SEM, FTIR and XRD analysis. The crystallinity of PCNC, CCNC and HCNC was found to be $81.1 \%, 75.4 \%$, and $86.1 \%$, respectively. The highly crystalline CNC II (PCNC) incorporation improved mechanical stiffness of raw hide trimming waste-based gelatin films by $50 \%$ compared to control gelatin film. Maximum thermal stability with $\mathrm{T}_{\max }$ of $329^{\circ} \mathrm{C}$ was obtained for gelatin films with PCNC nano-reinforcement. Strong interfacial hydrogen bonding interactions between gelatin and cellulose II nanocrystal existed and modified the properties of the film. Incorporation of CNC II reduced the surface wettability of the films and absorbed UV radiation as evidenced by transmittance value $T_{280}$ of 0.19 . Nanocomposite films degraded up to $79.9 \%$ of initial mass under 7 days of soil burial. Single use packaging application of garden eggplant seed has been demonstrated.

\section{Introduction}

Plastics are ubiquitous in every aspect of life. The plastic material is so prevalent in the recent times that the 20th and 21st centuries have justifiably been called the "Plastic age". The production and consumption of plastics, especially single use packaging plastics, have increased steadily over time. As a result, the accumulation of plastic as solid wastes in the environment is dangerously alarming. By 2050, its expected that roughly around 12 billion tons of plastic waste will end up in landfills or natural environment (Geyer et al. 2017). The plastic substrates photodegrade into micro-sized ( $<5 \mathrm{~mm}$ in size) under long exposure to UV radiation. These particulate matters pervade the environment and reach every stratum of the atmosphere. Primary sources of microplastics in the environment include microbeads generated from cosmetic products, large plastic wastes, microfiber from non-woven textile and sanitary product waste including wet wipes (Briain et al. 2020).

Research on biodegradable materials based on biopolymers or from renewable sources have been sought after as one of the plastic pollution abatement strategies, besides plastic recycling. Biopolymers, both protein and polysaccharide-based ones are the popular kind of plastic alternatives. Utilizing industrial wastes as renewable feedstock for preparing biodegradable plastic, would solve plastic pollution as well as waste accumulation issue.

Leather industry utilizes raw hides and skins as raw material with gallons of water and chemical inputs, in order to manufacture leather. As much as $35 \mathrm{~m}^{3}$ of wastewater and $800 \mathrm{~kg}$ of solid wastes are generated during the leather production from 1 ton of raw hides and skins (Kandasamy et al. 2020). Among the solid wastes, trimming wastes that are the unwanted offal pieces trimmed and disposed off, contribute to the major proportion. According to FAO report, around 418 thousand tons of raw trimming wastes is generated per year (FAO 2013). Trimming wastes are rich in protein in the form of collagen and 
hair keratin. These wastes have been exhaustively utilized for preparation of several low value and high value components applicable for leather manufacturing, polymeric applications, adhesive and textile application etc. (Sathish et al. 2019; Andonegi et al. 2020; Liu et al. 2011). The gelatin extracted from the trimming wastes would be a suitable biodegradable alternative owing to its multifunctional polyelectrolyte nature and film forming ability. Earlier, our research group has attempted the preparation of gelatin films with PVA, targeting to enhance its characteristics for packaging applications (Masilamani et al. 2017).

One of the most popular strength enhancement strategies include reinforcement of the gelatin matrix with functional nano-fillers. Cellulose nanocrystals (CNC) are polysaccharide-based nanomaterials that are used in many polymeric applications (Noorbakhsh-Soltani et al. 2018). CNCs can be extracted from several plant sources (Beltramino et al. 2015; Moran et al. 2008; Xu et al. 2013), agricultural wastes (De et al. 2021), and bacterial cellulosic sources (George \& Siddaramaiah, 2012). As a nanomaterial, CNC exhibit an array of properties such as high crystallinity, large surface area, biodegradability and large aspect ratio with surface functionalities. Cellulose is a linear homopolysaccharide composed of both crystalline and amorphous regions. The molecular orientation and functionalities in crystalline region vary widely giving rise to four major polymorphs of cellulose viz. cellulose I, cellulose II, cellulose III and cellulose IV. Majority of the native cellulose exists in the type I polymorph and can be converted to other polymorph type by chemical transformations.

Wet wipes are viscose textile-based materials that are marketed as biodegradable and ecofriendly. But these products form a significant component of global sewerage system blockages (Briain et al. 2020). Wet wipes have been part of everyday hygiene, gaining more attention ever so more since the COVID-19 pandemic. The viscose material is the mercerized form of cellulose that forms the raw material for wet wipe manufacturing. Mercerization of cellulose converts the cellulose I to cellulose II polymorph (Jin et al. 2016). In contrast to cellulose I, cellulose II has more stable structure making it suitable for several applications (Mansikkamaki et al. 2007). Cellulose II nanocrystals that has been extracted from mercerized Cellulose I, are renewable, biodegradable and non-toxic materials used in biomaterials due to its enhanced mechanical properties, low density and low thermal expansion (Du et al. 2019). Extraction of CNCs for biomaterial reinforcement conventionally uses strong mineral acids such as sulfuric acid that leads to over degradation of cellulose, large quantities of water and large amount of salt disposal as waste that are difficult to recover and reuse (Chen et al. 2016). Alternative to strong sulfuric acid, using mild mineral acid (hydrochloric acid) and organic acids have been reported so far (Jiang et al. 2010).

In the present work, for the first time, we report the extraction of cellulose II nanocrystal (CNC II) from wet wipe cellulose using three different mild hydrolysis techniques and characterized for its reinforcement efficiency on physical and chemical properties of trimming waste-based gelatin nanocomposite films. The nanocomposite films were also characterized for their biopolymeric functionalities to replace conventional plastic substrates as single use packaging material.

\section{Materials And Methods}




\subsection{Materials}

Delimed dehaired bovine trimming wastes were collected from Leather Processing Technology Department (LPTD), CSIR-CLRI, India. Wet tissue wipes were procured from the brand Kara wet wipes. Analytical grade Sodium Hydroxide pellets and Sodium Silicate were procured from M/s S-D Fine Chem Ltd., and Sodium Dodecyl Sulphate (SDS) was obtained from M/s HIMEDIA. Dihydrogen Peroxide (99.5\% purity) was obtained from M/s Merck. Acetic acid and Citric acid were obtained from SRL chemicals (Chennai, India). Soil (20\% moisture) was procured from a local garden in Chennai, India.

\subsection{Methods}

\subsubsection{Preparation of high bloom strength gelatin from trimming wastes}

High bloom strength gelatin was extracted from the pre-treated bovine trimmings according to the method described by Masilamani et al. 2017, with slight modifications. Briefly, the extraction of gelatin was carried out using $0.5 \mathrm{M}$ acetic acid at a temperature of $70^{\circ} \mathrm{C}$ for $7 \mathrm{~h}$ under thermo-regulated water bath setup. Gelatin in solubilized form was filtered using double mesh cloth and collected in a polystyrene tray, kept for drying at room temperature for $16 \mathrm{~h}$. The dried gelatin film was peeled off the tray and pulverized to form gelatin powder.

\subsubsection{Pretreatment of wet wipes}

Wet wipes were taken from the pack and dried at $60^{\circ} \mathrm{C}$ for $12 \mathrm{~h}$ to remove all moist components including fragrance from the wipes. The dried weight was noted, and a known number of dried wipes were manually shredded into pieces of size $2 \times 2 \mathrm{~cm}$. A known amount of dried shredded pieces was added to the pretreatment solution that was carried out in a $250 \mathrm{~mL}$ solution of $2 \% \mathrm{w} / \mathrm{v} \mathrm{NaOH}, 5 \% \mathrm{w} / \mathrm{v}$ sodium silicate, $0.06 \% \mathrm{w} / \mathrm{v}$ SDS at $80^{\circ} \mathrm{C}$ at constant stirring for $4 \mathrm{~h}$. The obtained pulp was quenched with $750 \mathrm{~mL}$ cold water, washed and filtered with deionized water several times using Buchner funnel until neutrality of $\mathrm{pH}$. The pulp mass was then transferred to pre-weighed crucible and dried at $60^{\circ} \mathrm{C}$ for 16-17 $\mathrm{h}$. The yield of cellulosic pulp was calculated based on the weight difference calculation before and after the process.

\subsection{Extraction of cellulose nanocrystals by hydrolysis methods}

\subsubsection{Alkaline peroxide method}

Under this method, the hydrogen peroxide $3 \% \mathrm{w} / \mathrm{v}$ was added dropwise to the dried shredded wet wipes submerged in the pretreatment solution and stirred vigorously at $80^{\circ} \mathrm{C}$ for $4 \mathrm{~h}$. The resultant turbid solution with cellulose nanocrystal (CNC) was quenched with cold water and filtered as described in previous section. 


\subsubsection{Acidic hydrolysis method}

The pretreated cellulose pulp was taken as starting material for acid catalysed hydrolysis method. Hydrolysis using citric acid catalyst was carried out using slightly modified method from Nagarajan et al. 2020. Briefly, citric acid solution ( $76 \% \mathrm{w} / \mathrm{v})$ was prepared and heated at $80^{\circ} \mathrm{C}$ for $30 \mathrm{~min}$. After the homogeneous solution is prepared, $2 \mathrm{~g}$ of pretreated pulp was added to the hot citric acid solution and stirred for $4 \mathrm{~h}$. The reaction was quenched by adding $250 \mathrm{~mL}$ of cold deionized water $\left(10 \pm 2{ }^{\circ} \mathrm{C}\right)$ and then washed and filtered several times until the $\mathrm{pH}$ was neutral. The nanocellulosic components were then dried at $60^{\circ} \mathrm{C}$ for $17 \mathrm{~h}$.

Another set of acid catalyzed hydrolysis of pretreated cellulose pulp was carried out using $3 \mathrm{M} \mathrm{HCl}$ solution at 1:30 w/v cellulose to solution ratio. The pulp was added to the acid solution and left to be static for $15 \mathrm{~min}$. The mixture was stirred for $45 \mathrm{~min}$ at $450 \mathrm{rpm}$ at $80^{\circ} \mathrm{C}$. The nanocellulose was then separated in dry state as described above.

Yield of the extracted cellulose nanocrystals was calculated by weight ratio between dried nanocellulose and initial weight of pretreated cellulosic pulp taken for hydrolysis reaction.

\subsection{Characterization of CNCs}

\subsubsection{Particle size analysis}

The particle size distribution of cellulose nanocrystals was determined by dynamic light scattering (DLS) using Zetasizer Nano ZS (Malvern Instruments Ltd.,). Nanocrystals were first dispersed in water to give $0.04 \% \mathrm{wt} \%$ solution for size determination.

\subsubsection{Morphological assessment (FE-SEM) and light transmittance of CNC II}

The surface morphological assessment of the cellulose nanocrystal was analyzed using Field EmissionScanning Electron Microscope (FE-SEM, TESCAN CLARA, Czech Republic) operated at $80 \mathrm{kV}$ acceleration voltage. $0.01 \mathrm{wt} \% \mathrm{CNC}$ suspension prepared with Millipore water and the aqueous suspension was sonicated for $5 \mathrm{~min}$. A drop of sonicated suspension was deposited onto the stub and sputter coated with $5 \mathrm{~nm}$ colloidal gold for dimensional analysis. Light transmittance of $0.1 \mathrm{wt} \% \mathrm{CNC}$ suspension was observed using UV-Vis spectrophotometer (JASCO V760) at $600 \mathrm{~nm}$.

\subsubsection{X-ray Crystallography of nanocellulose (XRD)}

The crystallinity index was determined by X-ray diffraction by Miniflex II Desktop X-ray Diffractometer (Rigaku, Japan). The samples were exposed to the $X$-ray beam irradiated at voltage of $30 \mathrm{kV}$ and $15 \mathrm{~mA}$ current. Scattered radiation was detected at ambient temperature in the angular region (20) of $5-80^{\circ}$ at a rate of $5^{\circ} / \mathrm{s}$ and a step size of $0.02^{\circ}$. Segal's method (Segal et al. 1959) was used to calculate the crystallinity index (Crl) by using the following equation 
$C r I=\frac{I(a c)-I(a m)}{I(a c)} \times 100$ Eq. 1

where $\mathrm{I}_{(\mathrm{ac})}$ is the maximum intensity of the peak (020), and $\mathrm{I}_{(\mathrm{am})}$ is the lowest intensity between the plane (110) and (020).

The crystallite size was estimated from XRD patterns using Scherrer equation (Normand et al. 2014) $D_{h k l}=\mathrm{K} \lambda / \beta_{1 / 2} \cos \theta \mathrm{Eq} .2$

where $D_{h k l}$ is the crystallite dimension in the direction normal to the $(h k l)$ lattice planes, $\mathrm{K}$ is the Scherrer constant equal to $0.9, \lambda$ is the radiation wavelength $(\lambda=0.154 \mathrm{~nm}$ for $\mathrm{Cu} \mathrm{Ka}), \theta$ is the diffraction angle and $\beta_{1 / 2}$ is the peak width at the half-maximum intensity in radians.

\subsubsection{Spectral characterization of nanocellulose (FTIR)}

The hydrolysed cellulose from wet wipes was structurally analyzed using FTIR spectrophotometer (JASCO FT/IR 4200) by KBr method. The FTIR spectra of all samples were recorded in the wave band ranging between 4000 and $400 \mathrm{~cm}^{-1}$ and at a resolution of $4 \mathrm{~cm}^{-1}$.

\subsection{Preparation of nanocomposite blend films}

Nanocomposite film using trimming waste gelatin and wet wipe nanocellulose were prepared by solution casting technique. $1 \mathrm{~g}$ of waste extracted gelatin was dissolved in $5 \mathrm{~mL}$ of $0.5 \mathrm{M}$ acetic acid solution and stirred for $45 \mathrm{~min}$ at $40^{\circ} \mathrm{C}$. Cellulose nanocrystal from each batch of hydrolysis was added at concentration levels of $5 \%, 10 \%$ and $15 \%$ (weight based on gelatin). The nanocellulose suspension was prepared by adding the required amount of CNC to $5 \mathrm{~mL}$ of distilled water and stirred for $45 \mathrm{~min}$ at room temperature. The gelatin solution was then added to the cellulose suspension and glycerol $(20 \% \mathrm{w} / \mathrm{w}$ of total solids) was added as plasticizer. This composite blend was stirred continuously at $40^{\circ} \mathrm{C}$ for $30 \mathrm{~min}$ and poured on levelled petri dishes of $9 \mathrm{~cm}$ diameter. The dried nanocomposite films were later peeled off and conditioned at $25^{\circ} \mathrm{C}$ until further characterizations.

\subsection{Characterization of films}

\subsubsection{Mechanical properties of films}

Thickness, tensile strength and elongation at break values were evaluated for all the nanobiocomposite films with a Universal Testing Machine (Instron 3369/J7257, controlled by Blue-hill software, version 3). Specimens of size $5 \times 1 \mathrm{~cm}$ were cut from the film samples. The gauge separation was kept as $30 \mathrm{~mm}$. The crosshead speed was at $25 \mathrm{~mm} / \mathrm{min}$. The tests were carried out at $25^{\circ} \mathrm{C}$ temperature and $50 \%$ relative humidity. Three specimens from each sample were taken and average with standard deviation are reported.

\subsubsection{ATR-FTIR characterization of films}


All nanocomposite film samples were analysed by FTIR spectrophotometer (JASCO FT/IR 4200) operating in the attenuated total reflectance (ATR) mode. Spectra was recorded at $4000-400 \mathrm{~cm}^{-1}$ region at a resolution of $4 \mathrm{~cm}^{-1}$ at room temperature. The empty crystal was used as a background. The angle of incidence for ATR crystal was $45^{\circ}$.

\subsubsection{Thermal characterization of films}

Thermogravimetric analysis (TGA) was carried out on a Q50 equipment (TA instruments, Waters Austria) using a heating rate of $10^{\circ} \mathrm{C} / \mathrm{min}$ from $25^{\circ} \mathrm{C}$ to $600^{\circ} \mathrm{C}$ under synthetic air atmosphere. A measured quantity of $5 \mathrm{mg}$ sample was conditioned in a ventilated climatic chamber at $25 \pm 2{ }^{\circ} \mathrm{C}$ and $50 \pm 5 \% \mathrm{RH}$ for $48 \mathrm{~h}$.

Differential Scanning Calorimeter (DSC) (Q200, TA instruments, Waters, Austria) was used to determine thermal properties of bionanocomposite films. Sample weighing $5 \pm 0.3 \mathrm{mg}$ was taken from the film samples and placed in sample pan with an empty reference pan. Samples were scanned at a heating rate of $10^{\circ} \mathrm{C} / \mathrm{min}$ from $30^{\circ} \mathrm{C}$ to $300^{\circ} \mathrm{C}$, under nitrogen atmosphere, to determine the thermal stability of films.

\subsubsection{Transparency and optical properties of films}

Transparency of the gelatin-CNC films were recorded using UV-Vis spectrophotometer (JASCO V760). Samples of size $4 \mathrm{~cm} \times 0.9 \mathrm{~cm}$ were cut from each batch and transmittance (\%T) at $600 \mathrm{~nm}$ was recorded in triplicates according to ASTM 2003. Transparency $\left(T_{600}\right)$ was determined as per the following equation

$T=-\log \left(T_{600}\right) / x$ Eq. 3

where ' $x$ ' is the film thickness (in $\mathrm{mm}$ ).

Transmittance between 200 and $800 \mathrm{~nm}$ was also measured using spectrophotometer to determine UVVis barrier ability. Light barring capacity of the films were determined at wavelength $280 \mathrm{~nm}$ and $660 \mathrm{~nm}$.

\subsubsection{Moisture sensitivity of films}

To determine the moisture content, $1 \mathrm{~cm} \times 1 \mathrm{~cm}$ square sized specimens were cut from the composite films of each batch. The initial weight was noted to be $W_{0}$. The specimen was dried at $100^{\circ} \mathrm{C}$ for $24 \mathrm{~h}$. The weight was recorded to be $W_{1}$. The weight loss expressed in percentage relative to the initial weight is given as moisture content (Eq. 2). The dried samples were then immersed in $10 \mathrm{~mL}$ of distilled water and incubated at ambient temperature for $3 \mathrm{~h}$. Decanting the water out, the weight of the swollen matrix was recorded as $\mathrm{W}_{2}$, and finally, the matrix was oven dried at $100^{\circ} \mathrm{C}$ for $24 \mathrm{~h}$, and the resultant weight was recorded as $W_{3}$. The following calculations were done, to determine the initial moisture retention, swelling, and solubility of the composite films.

InitialMoisturecontent $=\frac{W_{1}-W_{0}}{W_{0}} \times 100 \mathrm{Eq} .4$ 
Swellingpercentage $=\frac{W_{2}-W_{1}}{W_{1}} \times 100$ Eq. 5

Solubility $=\frac{W_{3}-W_{1}}{W_{3}} \times 100$ Eq. 6

\subsubsection{Water contact angle}

For determining water contact angle of composite film, $1 \mathrm{~cm} \times 1 \mathrm{~cm}$ flat samples were cut from each batch and attached to the platform of contact angle meter. $5 \mu \mathrm{L}$ of distilled water was dropped onto both sides of the sample and image was captured. ImageJ software was used to measure the contact angle from the droplet images.

\subsection{Biodegradability of films}

Biodegradation under soil burial conditions were carried out under laboratory scale following the methodology as proposed by ASTM D6400 (Luchese et al. 2021). Samples of size $2 \times 2 \mathrm{~cm}$ were weighed and covered with a thin gauze pocket with label. These samples were buried under soil (20\% moisture) in a pot at a depth of $4 \mathrm{~cm}$ to assure aerobic degradation. The soil was moistened with water once a day. The sample from each batch was removed from soil and dried in an oven at $50^{\circ} \mathrm{C}$ for $2 \mathrm{~h}$. The biodegradation rate was calculated by the weight loss percentage at the final day of observation. The digital images of the degraded samples were captured to record the biodegradation.

\subsection{Packaging potential of films}

A sample of prepared film (control gelatin and GPCNC15) was thermally sealed with heat sealing machine with seeds of eggplant. The sealed packets were maintained at room temperature to monitor the performance of the films as disposable packaging films.

\subsection{Statistical analysis}

Statistical analysis of the data was evaluated using GraphPad Prism 8 (GraphPad Inc., San Diego, CA, USA). All data are reported as mean and standard deviation for triplicates. One -way ANOVA (analysis of variance) was conducted to determine the statistical significance at $p<0.05$ ( $95 \%$ confidence) level. Post hoc Tukey's test was done followed by ANOVA to compare the means of different groups for identifying the significant differences at $p<0.05$.

\section{Results And Discussion}

\subsection{Characterization of cellulose nanocrystal (CNC) from wet wipes}

\subsubsection{Yield, particle size and zeta potential of CNC}

Figure 1. Schematic illustration of cellulose II nanocrystal preparation from wet wipes 
The schematic for preparation of cellulose II nanocrystal from wet wipes is illustrated in Fig. 1. The current strategy of CNC II preparation without use of mercerization was done under least number of purification steps. The simple process of Buchner filtration with few cycles of washing for neutralization was carried out for CNC II purification. The yield, particle size and zeta potential of pretreated pulp and CNCs are given in Table 1. The yield of pretreated pulp from dried wet wipe was determined as $72 \%$. The pretreated pulp devoid of chemicals from the wet wipe was used as precursor for the CNC preparation. The yield from peroxide treatment was found to be $66 \%$. This was higher than the yield of cellulose nanoparticles prepared from softwood pulp by $\mathrm{H}_{2} \mathrm{O}_{2}$ oxidation (54\%) (Koshani et al. 2018). The yield of CCNC was found to be $81 \%$. The citric acid at $76 \%$ wt $\%$ was sufficient to cleave the glycosidic bonds between the fibrils leading to depolymerization and high recovery of cellulose nanocrystal. The current work led to higher yield of CCNC compared to the previous reports (Nagarajan et al. 2020; Ji et al. 2019). The hydrochloric acid-based CNC extraction method resulted in $77 \%$ yield. The mineral acid treatment showed relatively less yield than organic acid. Higher yields with different neutralization methods have been reported earlier (Yu et al. 2013).

Table 1

Characterization of CNC prepared by different hydrolysis techniques

\begin{tabular}{|lllllll|}
\hline Sample & $\begin{array}{l}\text { Particle Size } \\
(\mathrm{nm})\end{array}$ & $\begin{array}{l}\text { Zeta Potential } \\
(\mathrm{mV})\end{array}$ & $\begin{array}{l}\text { Yield } \\
(\%)\end{array}$ & $\begin{array}{l}\text { CS } \\
(\mathrm{nm})\end{array}$ & $\begin{array}{l}\text { Crl } \\
(\%)\end{array}$ & $\begin{array}{l}\text { CrR } \\
(\%)\end{array}$ \\
\hline Pretreated Pulp & - & - & 72 & 2.35 & 62.0 & 0.804 \\
\hline PCNC & 248.7 & -23.0 & 66 & 4.49 & 81.1 & 0.265 \\
\hline CCNC & 141.8 & -19.9 & 81 & 5.39 & 75.4 & 0.216 \\
\hline HCNC & 128.7 & -24.9 & 77 & 5.5 & 86.1 & 2.565 \\
\hline
\end{tabular}

The average hydrodynamic diameter of PCNC, CCNC and HCNC were observed to be $248.7 \mathrm{~nm}, 141.8 \mathrm{~nm}$ and $128.7 \mathrm{~nm}$, respectively. Hydrogen peroxide hydrolysis degraded the substrate more uniformly and produced CNC II as long cylinders corresponding to bundles of nanofibrils. Similar effect was observed when CNC was extracted using catalytic peroxide oxidation (Koshani et al. 2018). The particle size analysis of CCNC and HCNC revealed their corresponding hydrodynamic diameter to be $141.8 \mathrm{~nm}$ and $128.7 \mathrm{~nm}$ respectively. The smaller particle size is the result of efficient hydrolysis by both organic and mineral acid.

The zeta potential values of CNC provide evidence for the net charges present on the surface of the nanoparticle as function of $\mathrm{pH}$. The charge on the surface determines the dispersion stability of a colloidal system comprising of CNC. Colloidal solution with zeta potentials less than $-30 \mathrm{mV}$ and more than $+30 \mathrm{mV}$ could maintain a stable system due to repelling forces between particles (Lin et al. 2019). The charges are result of type of hydrolyzing method employed to extract CNC. The peroxide and citric acid treatment is expected to attach carboxylate group to the CNC surface. The zeta potential value for PCNC and CCNC were found to be $-23 \mathrm{mV}$ and $-19.9 \mathrm{mV}$, respectively. The value of PCNC was found 
closer to the value of carboxylated CNC prepared by APS oxidation (Cheng et al. 2014). Similar values were observed when carboxylated CNCs, which were obtained using iron catalyzed peroxide hydrolysis (Fan et al. 2019). The lowest zeta potential value was observed for CCNC (-19.9 mV). The low value indicates the lower content of carboxylic groups that were created by esterification of hydroxyl groups of CNC (Nagarajan et al. 2020). The previous reports, however, presented CNC with higher zeta potential values (in the range of 90-123 mV) when only citric acid was used (Ji et al. 2019) and when mixture of citric and hydrochloric acid was used, the value ranged between $-33 \mathrm{mV}$ and $-46 \mathrm{mV}$ (Yu et al. 2016). The zeta potential of HCNC was - $24.9 \mathrm{mV}$, which is comparatively better values than that of CNC obtained using hydrothermal hydrochloric acid-based hydrolysis followed by different neutralization techniques (Yu et al. 2013). The lack of surface charge creation by hydrochloric acid method is usually considered a drawback compared to conventional sulfuric acid method, as it could lead to aggregation of CNCs thereby resulting in poor colloidal stability. The zeta potential values of HCNC suggested moderate to good dispersion stability. CNCs with good stability will enhance its applicability in variety of applications ranging from wastewater treatment to composite reinforcement.

\subsubsection{Morphological characterization}

The microstructural characteristics of the prepared CNCs were observed using FE-SEM and the micrographs are given in Fig. 2A-C (low magnification) and Fig. 2a-c (high magnification). The CNC samples exhibited typical rod-like morphology with high length to diameter ratio. Citric acid treatment rendered CNC with thin needle like morphology (Fig. 2B). This was due to the acid penetrating the amorphous region of cellulose, leaving the ordered crystalline nanoparticles in longitudinal direction ( $\mathrm{Ji}$ et al. 2019). These needle shaped nanoparticle tend to form web like structures that had enhanced physical properties of composite films reported recently (Lu et al. 2021). The rod like structure of obtained CNC confirmed the efficiency of the mild extraction methods that resulted in highly crystalline entities (Yu et al. 2013).

The prepared cellulose II nanocrystal suspension ( $0.1 \mathrm{wt} \%)$ exhibited a colloidal state when observed under ambient conditions (Fig. 3). The transmittance of PCNC, CCNC, and HCNC was found to be $71.13 \%$, $74.06 \%$ and $69.5 \%$ at $600 \mathrm{~nm}$ wavelength, respectively. The translucent appearance of colloidal suspension well reflected in the UV-Vis spectrometer. The findings were similar to the cellulose II nanocrystal suspension prepared from sulfuric acid hydrolysis of eucalyptus cellulose (Xing et al. 2020).

\subsubsection{Crystallography of CNC}

The XRD pattern of pretreated cellulose pulp, PCNC, CCNC and HCNC is given in Fig. 4. All samples exhibit key diffraction peaks at $2 \theta \approx 12.2^{\circ}, 20^{\circ}$ and $21.7^{\circ}$ corresponding to $1-10,110$ and 020 planes, respectively. These are the characteristic peaks for cellulose type II polymorph (Gong et al. 2017; Lu et al. 2021). The intense double peak in CNCs compared to that of pretreated pulp confirms the efficiency of extraction methods in hydrolyzing the amorphous regions, leaving out the rigid crystalline region. The crystallinity index and crystallite size of the CNCs are given in Table 1. The crystallinity (Crl) of pretreated pulp, PCNC, CCNC and HCNC were found to be $62 \%, 81.1 \%, 75.4 \%$ and $86.1 \%$ respectively. The 
crystallinity of PCNC is high and close to the CNCs prepared using catalytic oxidation using peroxide (Koshani et al. 2018) and that of the ones prepared using conventional acid hydrolysis from bleached soft wood kenaf ( $\mathrm{Li}$ et al. 2011). The Crl of CCNC was comparatively lower than other two methods. This could be because of carboxylic acid released during the reaction between citric acid and cellulose, which affected some of the crystalline region too (Nagarajan et al. 2020). The HCNC were prepared with high order of crystallinity. Hydrochloric acid is less aggressive than sulfuric acid, thus attacks crystalline region less, just as in the case with other mild acids (Yu et al. 2013). The crystallinity of CNC II was found to be higher compared to the previous research (Mahmud et al. 2019; Lu et al. 2021; SaifulAzry et al. 2021). The crystallite size (CS) of the CNCs followed the similar trend as that of crystallinity. Pretreated cellulose pulp with lower crystallinity have smaller crystallite size in crystalline region. The values were found closer to the crystallite size of CNC II obtained by Jin et al. 2016 (Jin et al. 2016). The crystallite size of CNC II prepared from medical cotton using $85 \%$ phosphoric acid were observed in the range of $10.02 \mathrm{~nm}$ and $11.1 \mathrm{~nm}$ (Mahmud et al. 2019).

\subsubsection{FTIR spectroscopy of cellulose nanocrystal}

Figure 5a shows the FTIR spectrographs of wet wipe cellulose, PCNC, CCNC and HCNC. All the spectrum showed characteristic peaks at around 3600 and $3100 \mathrm{~cm}^{-1}$ associated with $-\mathrm{OH}$ bond stretching and peaks near $2900 \mathrm{~cm}^{-1}$ indicated $\mathrm{C}-\mathrm{H}$ stretching vibration. The spectra featured two distinct peaks at 3447 $\mathrm{cm}^{-1}$ and $3489 \mathrm{~cm}^{-1}$ which are characteristic of cellulose type II polymorph, indicating the intramolecular hydrogen bonds of cellulose II (Huang et al. 2021; Xing et al. 2020). The band at $1640 \mathrm{~cm}^{-1}$ and 1371 $\mathrm{cm}^{-1}$ is associated with $\mathrm{O}-\mathrm{H}$ bending of absorbed water and $\mathrm{C}-\mathrm{H}$ stretching vibration (Huang et al. 2021). The $C-0$ stretching band of pyranose $\left(C_{6}\right)$ unit at $1057 \mathrm{~cm}^{-1}$ was also observed (Mahmud et al. 2019). The peak at $1430 \mathrm{~cm}^{-1}$ is associated with $-\mathrm{CH}_{2}$ bending vibration of $\mathrm{C}_{6}$ which is known as "crystallinity" band of cellulose. The $895 \mathrm{~cm}^{-1}$ peak corresponds to C-O-C stretching vibration, considered as "amorphous" band, is indicative of cellulose type II (Lu et al. 2021; Mahmud et al. 2019). The intensified broad band at $3300 \mathrm{~cm}^{-1}$ in PCNC is due to the stretching vibration of $\mathrm{OH}$ groups, that emanated from hydrogen bond breaking during peroxide oxidation reaction (Koshani et al. 2018).

The crystallinity of wet wipe cellulose, PCNC, CCNC, and HCNC were calculated using ratio between absorption intensities at crystalline peak and amorphous peak. The CrR values are tabulated in Table 1. The crystallinity of HCNC was found to be maximum (2.565) among the other CNC and wet wipe cellulose. This is in congruence with the observation from X-ray crystallography studies where maximum intensity was observed for HCNC sample.

\subsection{Characterization of bionanocomposite film 3.2.1 Mechanical characterization of films}

Thickness and mechanical performance of all films are given in Table 2. The thickness of the films ranged between $150 \mu \mathrm{m}$ and $193.34 \mu \mathrm{m}$. There was no significant difference in thickness measurements 
of the films when compared to control gelatin film $(p>0.05)$. The tensile strength of the nanocomposite films had increased with the addition of CNC. The significant improvement in tensile strength values compared to the gelatin film was observed in G-PCNC (50.22\% increase) films and G-CCNC films (41.89\% increase). Generally, cellulose II is more reactive than cellulose I, and more hydrogen bonding interactions are possible (SaifulAzry et al. 2021). The reinforcement of PCNC and CCNC is the result of strong interfacial bonding between gelatin and CNC. The mechanical strength is dependent on the relative volume fractions of hard phase and soft phase. The high crystallinity of CNC makes it rigid and stiff that arrests the mobility of the polymer network. The rod like nanostructure with high aspect ratio enhanced the stiffness and reduced flexibility of the nanocomposite film, resulting in reduced elongation at break values. Similar kind of results were observed when CNC were used as reinforcement in potato starchbased film and soy protein isolate based films (Noshirvani et al. 2017; Huang et al. 2020). The increase in tensile strength by CNC could also be due to electrostatic attraction that exists between gelatin (at $\mathrm{pH} 3)$ and negatively charged CNC particle (Leite et al. 2020). The enhancement in mechanical properties by HCNC was not significantly different from the control gelatin film $(p>0.05)$. The smaller particle of HCNC dispersed well and increased the homogeneity that imparted not much of a difference in the physical properties. 
Table 2

Mechanical and optical properties of Gelatin-CNC films

\begin{tabular}{|c|c|c|c|c|c|}
\hline & $\begin{array}{l}\text { CNC II } \\
\text { Loading } \\
(\%)\end{array}$ & $\begin{array}{l}\text { Thickness } \\
(\mu \mathrm{m})\end{array}$ & $\begin{array}{l}\text { Tensile } \\
\text { strength } \\
\text { (MPa) }\end{array}$ & $\begin{array}{l}\text { Elongation at break } \\
\text { (\%) }\end{array}$ & $\begin{array}{l}\text { Transparency } \\
\left(\mathrm{A} \mathrm{mm}^{-1}\right)\end{array}$ \\
\hline Control & & $\begin{array}{l}176.67 \pm \\
15.27^{\mathrm{a}}\end{array}$ & $6.67 \pm 0.19^{a}$ & $134.20 \pm 7.31^{c}$ & $11.27 \pm 0.23^{d}$ \\
\hline \multirow[t]{3}{*}{$\begin{array}{l}\text { G- } \\
\text { PCNC }\end{array}$} & 5 & $\begin{array}{l}173.3 \pm \\
15.27^{a}\end{array}$ & $8.56 \pm 0.31^{b}$ & $97.69 \pm 14.31^{b}$ & $9.71 \pm 0.33^{c}$ \\
\hline & 10 & $\begin{array}{l}183.33 \pm \\
5.77^{a}\end{array}$ & $12.3 \pm 0.17^{c}$ & $72.4 \pm 1.31^{\mathrm{a}}$ & $7.02 \pm 0.11^{b}$ \\
\hline & 15 & $180 \pm 10^{\mathrm{a}}$ & $13.4 \pm 0.25^{\mathrm{d}}$ & $57.22 \pm 5.78^{a}$ & $5 \pm 0.13^{a}$ \\
\hline \multirow[t]{3}{*}{$\begin{array}{l}\text { G- } \\
\text { CCNC }\end{array}$} & 5 & $\begin{array}{l}156.67 \pm \\
11.54^{\mathrm{a}}\end{array}$ & $6.43 \pm 0.6^{a}$ & $98.98 \pm 17.92^{\mathrm{cd}}$ & $10.05 \pm 0.18^{g}$ \\
\hline & 10 & $\begin{array}{l}193.34 \pm \\
15.27^{a}\end{array}$ & $7.17 \pm 0.7^{a}$ & $76.3 \pm 16.2^{d}$ & $7.34 \pm 0.2^{f}$ \\
\hline & 15 & $\begin{array}{l}176.76 \pm \\
15.27^{a}\end{array}$ & $11.48 \pm 0.74^{\mathrm{e}}$ & $63.7 \pm 12.7^{d}$ & $6.41 \pm 0.21^{\mathrm{e}}$ \\
\hline \multirow[t]{3}{*}{$\begin{array}{l}\text { G- } \\
\text { HCNC }\end{array}$} & 5 & $150 \pm 10^{\mathrm{a}}$ & $8.82 \pm 0.32^{f}$ & $78.56 \pm 6.33^{\mathrm{e}}$ & $11.02 \pm 0.14^{d}$ \\
\hline & 10 & $170 \pm 20^{\mathrm{a}}$ & $8.51 \pm 0.66^{f}$ & $81.83 \pm 16.95^{\mathrm{e}}$ & $9.28 \pm 0.14^{i}$ \\
\hline & 15 & $\begin{array}{l}163.33 \pm \\
15.27^{a}\end{array}$ & $8.14 \pm 0.12^{f}$ & $84.5 \pm 5.05^{\mathrm{e}}$ & $7.47 \pm 0.31^{h}$ \\
\hline \multicolumn{6}{|c|}{${ }^{*}$ Mean \pm Standard deviation $(n=3)$} \\
\hline $\begin{array}{l}{ }^{\star *} \text { Diff } \epsilon \\
\text { mean }\end{array}$ & I? & scripts & e column & e significant differ & between \\
\hline
\end{tabular}

\subsubsection{ATR spectrographs of Gelatin-CNC composite films}

The ATR-FTIR spectrographs of control gelatin and nanocomposite films are shown in Fig. 5b. The main characteristic peaks were observed at $3500-2300 \mathrm{~cm}^{-1}$ corresponding to $\mathrm{OH}$ and $\mathrm{NH}$ stretching (amide A), $1640 \mathrm{~cm}^{-1}$ corresponding $\mathrm{C}=\mathrm{O}$ stretching (amide I), $1527 \mathrm{~cm}^{-1}$ related to $\mathrm{N}-\mathrm{H}$ bending (amide II) and $1238 \mathrm{~cm}^{-1}$ indicating C-N stretching (amide III) (Mondragon et al. 2015). The broad band at $3000 \mathrm{~cm}^{-1}$ also corresponded to free and bound $\mathrm{OH}$ from water molecule present in the films. The peak $2915 \mathrm{~cm}^{-1}$ observed due to stretching of $\mathrm{C}-\mathrm{H}$ of the cellulose molecule (Sasikala \& Umapathy, 2018). The peak at $1330 \mathrm{~cm}^{-1}$ is attributed to wagging of $-\mathrm{CH}_{2}$ of proline from the gelatin (Uranga et al. 2016). The band at 
$1032 \mathrm{~cm}^{-1}$ is associated with the interactions between glycerol and hydroxyl groups present in the film (Santos et al. 2014). No significant changes in peak intensities were observed between control gelatin and G-CNC films indicating the absence of very strong intermolecular modification amongst the polymeric components of the nanocomposite film.

\subsubsection{Thermal characterization of films}

Figure $6 \mathrm{a}$ and $6 \mathrm{~b}$ represent the TGA thermogram and derivative curve as dTG of control gelatin, GPCNC15, G-CCNC15 and G-HCNC15 respectively. The degradation profile of all the films majorly exhibited three phases. The first phase at around $80-100{ }^{\circ} \mathrm{C}$ was related to the evaporation of water and degradation of glycerol from the matrix. There occurs a small weight loss at this stage. The second phase is attributed to cellulose thermal degradation and the temperature at which the decomposition begins is termed as onset temperature $\left(T_{0}\right)$. The onset temperature for control gelatin and nanocomposite films were found to be above $250^{\circ} \mathrm{C}$, indicating good thermal stability. The third phase occurs when maximum decomposition of the matrix occurs, which is marked by the dTG curves. The $T_{\max }$ of control gelatin, G-PCNC15, G-CCNC15 and G-HCNC15 was observed to be $317^{\circ} \mathrm{C}, 329^{\circ} \mathrm{C}, 318^{\circ} \mathrm{C}$ and $315^{\circ} \mathrm{C}$ respectively. The thermal stability of films reinforced with $\mathrm{CNCs}$ were found to be better than control gelatin film. The CNCs in type II polymorph are inherently thermodynamically stable due to their packing structure (Jin et al. 2016; Wang et al. 2014). Also, higher thermal stability is associated with crystallinity as higher energy is required for thermal decomposition of highly crystalline material (Lu et al. 2021). The results are well in agreement with the crystallography results.

The effect of hydrolysis method of CNC has a significant effect on its thermal stability, which in turn reflects in the nanocomposite film. It is well known that surface sulfated groups created by sulfuric acid hydrolysis on the anhydroglucose unit require less energy, which could release sulfuric acid at much lower temperature during thermal degradation process. This released sulfuric acid would act as a catalyst in facilitating cellulose decomposition (Yu et al. 2013). The CNC prepared by sulfuric acid hydrolysis would therefore have lower thermal stability (Mahmud et al. 2019; Lei et al. 2017). The current work utilizes peroxide, citric acid and hydrochloric acid to extract $\mathrm{CNC}$, which were beneficial in providing better thermal stability. The char residue of GPCNC15, GCCNC15, GHCNC15 and control gelatin films were observed to be $19.71 \%, 19 \%, 20.05 \%$ and $15.8 \%$ at the end of thermal degradation process, indicating the enhanced flame resistance exhibited by the CNC-II (Gonzalez-Dominguez et al. 2019). The higher thermal stability offered by CNC in a nanocomposite would widen its scope of applicability in various fields.

\subsubsection{Differential Scanning Calorimetry (DSC)}

DSC thermograms of control gelatin film and bionanocomposite films with $15 \% \mathrm{CNC}$ II is given in Fig. 7 . The spectra of films exhibited endothermic peaks occurring at around $89-100^{\circ} \mathrm{C}$, which is attributed to water evaporation, and molecular relaxation at such temperature overlapping the $\mathrm{T}_{\mathrm{g}}$ of gelatin component (approximated at around $75-80^{\circ} \mathrm{C}$ ) (Masilamani et al. 2017; Mondragon et al. 2015). This was in line with the observations from TGA. Another endothermic peak at $250^{\circ} \mathrm{C}$ is observed for gelatin film and GCCNC15, which is attributed to melting temperature of the composite film caused due to the 
devitrification of proline and hydroxyproline imino acids. In case of GPCNC15 film, this peak shifted to slightly lower temperature indicating the recrystallization induced by nanocrystals that acted as nucleating agent in protein films (Hosseini et al. 2015). The changes in temperature in GHCNC15 film was insignificant.

\subsubsection{UV-Vis and Transparency properties of films}

UV-Vis transmittance exhibited by control gelatin film and nanocomposite films are given in Fig. 8. All films including control gelatin film showed excellent light barrier properties, specifically in UVC (200-280 $\mathrm{nm}$ ) region. This is due to the presence of chromophore groups such as tyrosine and phenylalanine amino acid groups in gelatin network, which have unsaturated bond that absorb UV radiation (Chuaynukul et al. 2018). Addition of CNC to the gelatin film, decreased the light transmittance in both UV and Visible light radiation region to a considerable extent. The light transmittance reduced significantly with increase in concentration of CNC, which is evident from the plot where all films with $15 \%$ wt\% CNC showed transmittance below $20 \%$. The presence of hydroxyl group from the CNC act as auxochrome when conjugated with the pre-existing chromophore from the gelatin, absorbs more light (Uranga et al. 2016). The opacity of the films is also dependent on the crystalline character and the particle size of the nanocrystal. The least light transmission observed with G-PCNC15 film was due to the high crystallinity and hindrance caused due to agglomeration of PCNC particle at high concentration (Haghighi et al. 2020; Alves et al. 2014). The scattering of light is more at such concentration than reflection. The shielding effect by films with CCNC could be due to few conjugated carboxyl and carbonyl groups formed at the pyranose ring of $\mathrm{CNC}$ during citric acid treatment. These group act as chromophores in absorbing light radiation (Yang et al. 2020).

The transparency at $600 \mathrm{~nm}$ was calculated and tabulated in Table 2. The highest value of transparency (11.27 $\mathrm{A} \mathrm{mm}^{-1}$ ) was obtained for control gelatin film. The value of transparency decreased with increase in CNC concentration $(p<0.05)$. The reduction in light transmission was very small in case of G-HCNC films. This indicated the better dispersion of HCNC in gelatin matrix compared to other CNC. Homogeneity and compatibility between HCNC and gelatin were better, that led to light transmission similar to the control gelatin film (Pei et al. 2013).

\subsubsection{Optical light transmittance of nanocomposite films}

The light transmittance of nanocomposite films in the UV $(280 \mathrm{~nm})$ and visible range $(660 \mathrm{~nm})$ is given in Table 3. The light barring character of gelatin films was significantly decreased with increasing nanocrystal concentration $(p<0.01)$. GPCNC15 film had the least $T_{660}$ value of $8.2 \%$. The UV barrier capability was found to be excellent for all composite films with $T_{280}$ values below $2 \%$. Addition of nanocrystals improved the UV barrier further, rendering the GPCNC15 film with the most UV blocking capacity with a value of $0.19 \%$. These values were better than the food packaging carrageenan films with $\mathrm{TiO}_{2}$ nanotubes reinforcement with UV transmittance 9.1\% and light transmittance $31.1 \%$ (Ezati et al. 2021). Light blocking including UV is a key requirement for packaging materials, as light could cause photodecomposition of food, oxidation and rancidity of the packed food material reducing its viability for 
consumption. The prepared nanocomposite films are beneficial as packaging materials with such outstanding UV and light barrier characteristics.

Table 3

Light transmittance of Gelatin-CNC films

\begin{tabular}{|c|c|c|c|c|}
\hline \multirow[t]{2}{*}{ CNC II loading } & \multicolumn{4}{|l|}{$\mathrm{T}_{660}(\%)$} \\
\hline & $5 \%$ & $10 \%$ & $15 \%$ & Control \\
\hline GPCNC & $50.5 \pm 0.7^{c}$ & $20.9 \pm 0.08^{b}$ & $8.2 \pm 0.3^{a}$ & \multirow[t]{3}{*}{$87.8 \pm 0.6^{d}$} \\
\hline GCCNC & $40.78 \pm 0.7^{c}$ & $28.04 \pm 0.5^{b}$ & $18.2 \pm 0.2^{\mathrm{a}}$ & \\
\hline GHCNC & $48.1 \pm 0.5^{c}$ & $38.8 \pm 0.6^{\mathrm{b}}$ & $18.1 \pm 0.2^{\mathrm{a}}$ & \\
\hline \multirow[t]{2}{*}{ CNC II loading } & \multicolumn{4}{|l|}{$\mathrm{T}_{280}(\%)$} \\
\hline & $5 \%$ & $10 \%$ & $15 \%$ & Control \\
\hline GPCNC & $1.83 \pm 0.05^{\mathrm{c}}$ & $0.56 \pm 0.02^{b}$ & $0.19 \pm 0.02^{\mathrm{a}}$ & \multirow[t]{3}{*}{$1.82 \pm 0.06^{\mathrm{c}}$} \\
\hline GCCNC & $1.21 \pm 0.04^{d}$ & $0.76 \pm 0.04^{b}$ & $0.36 \pm 0.02^{a}$ & \\
\hline GHCNC & $1.74 \pm 0.02^{c}$ & $0.62 \pm 0.03^{b}$ & $0.34 \pm 0.03^{a}$ & \\
\hline \multicolumn{5}{|c|}{${ }^{*}$ Mean \pm Standard deviation $(n=3)$} \\
\hline
\end{tabular}

\subsubsection{Moisture sensitivity of films}

Moisture sensitivity, evaluated with help of moisture content, degree of swelling and solubility of films in aqueous environment is given in Table 3. The moisture content of the films ranged between $12.47 \%$ and $15.81 \%$. The inherent moisture content was slightly higher for films with lower concentration of CNC in all three cases, when compared to control gelatin films. The detectable moisture level decreased with increase in CNC concentration. This could be attributed to the presence of higher amounts of water insoluble cellulose nanocrystal in the gelatin matrix. 
Table 4

Moisture sensitivity and water contact angle of Gelatin-CNC films

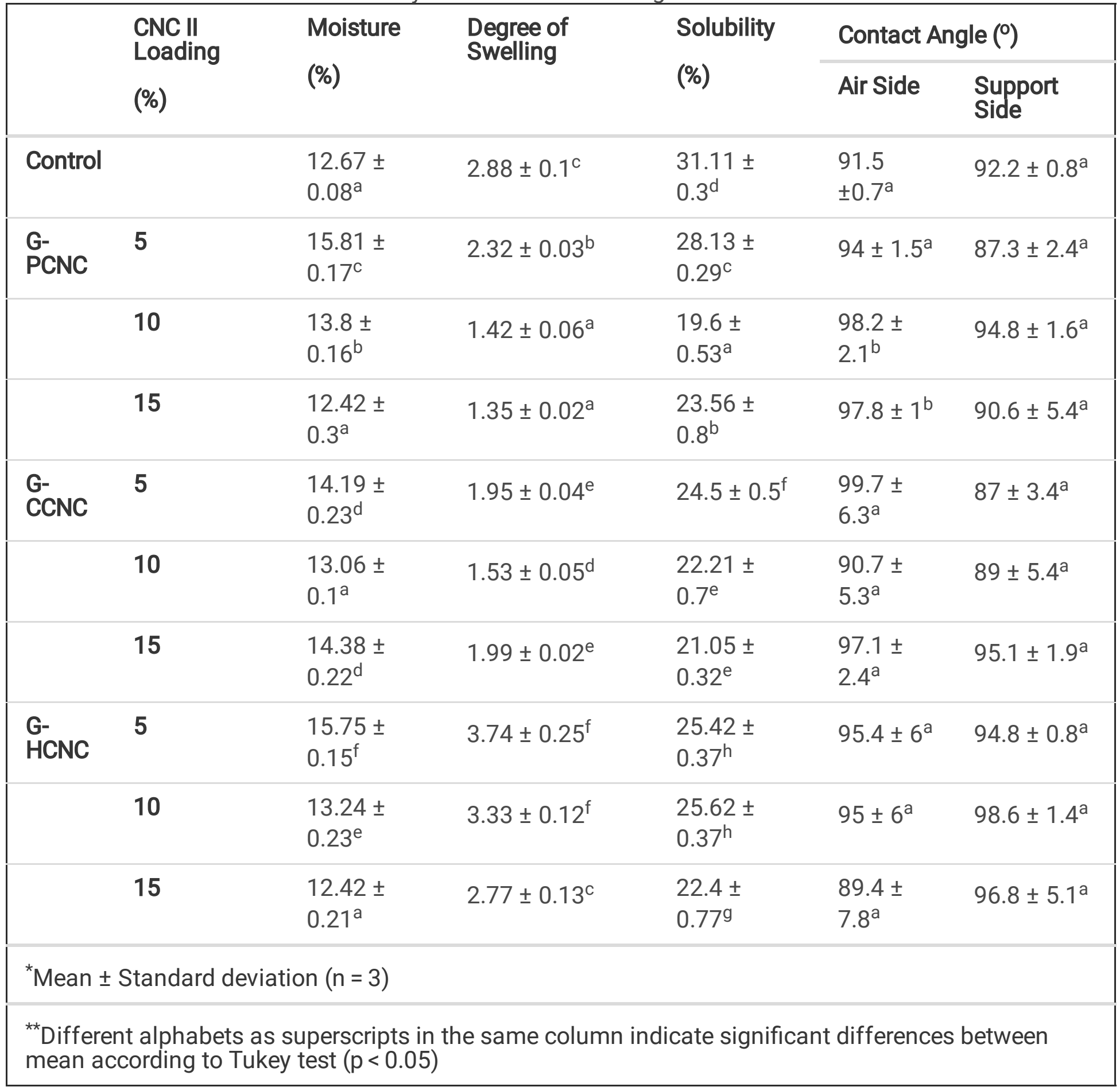

Degree of swelling represents the moisture uptake by the nanocomposite films. Moisture resistance by the G-PCNC and G-CCNC films were observed to be better than the control gelatin film. At lower concentrations, the strong interfacial adhesion between the cellulose nanocrystal and the polar group of gelatin prevented moisture absorption. The agglomeration of the $\mathrm{CNC}$ at high concentration did not result in significant improvement in moisture uptake $(p<0.05)$. Similar trend of result was observed when CNC prepared from garlic stalks were used as reinforcement in starch-based biopolymer film (Agustin et al. 2013). 
Solubility of nanocomposite films was found to be lower than that of control gelatin films. The reduction of solubility at lower loading levels of CNCs was evident from the Table 4. Such improvement is due to the Gel-CNC complex coacervates formation that occurred with gelatin being present at $\mathrm{pH} 3$. This complexation reduced charged interaction and prevented moisture uptake (Leite et al. 2020). The strong hydrogen bond formation between the hydroxyl groups and polar groups of the gelatin created threedimensional network limiting the mobility of the water molecule, thereby reducing the solubility (Noshirvani et al. 2017). Amorphous regions of CNC are more prone to moisture absorption than crystalline region. With use of highly crystalline nanocellulose, improvement in moisture sensitivity was inevitable (Pereira et al. 2017).

\subsubsection{Water Contact angle}

The contact angle measurements on the either side of the nanocomposite film depicts the wettability of the surface (Table 4). The "air side" of the film represents the exposed side of the film from the petri dish, whereas the "support side" denotes the side attached to the petri dish. The control gelatin film exhibited contact angle above $90^{\circ}$, despite the hydrophilic character of the polymeric matrix. Incorporation of CNC improved the hydrophobicity of the films. The differences in the water contact angle values on either side of the films were predominantly observed in the case of G-PCNC films. This could be due to the comparatively bigger sized nano-rod like CNC that formed an interconnected pseudo bilayer on the surface of the film, which created a rough surface on one side. Rough surfaces modulate the contact angle as they contain air fractions that prop up water droplet from the surface increasing the water contact angle. Such rough surfaces can exhibit better hydrophobicity and may increase the tortuosity for water molecules making the film water impermeable. It was demonstrated in previous research that assembly of hydrophilic nanocellulose and nano-clay surfaces led to increased water contact angle (Wu et al. 2014).

In case of G-HCNC films, the dispersion of CNC within gelatin network was better and no significant improvement in water contact angles were observed when compared to control gelatin films $(p<0.05)$. The results were in line with the observations from light transmission experiment. The strong hydrogen bonding interaction between hydroxyl group of highly crystalline CNC and gelatin contributed to improved wettability characteristics (Noshirvani et al. 2017; Coelha et al. 2020). Similar trend of results was observed when bovine gelatin was reinforced with $2.5 \%$ CNC that improved water contact angle value to $95.2^{\circ}$ from $80.7^{\circ}$ for control gelatin film (Leite et al. 2020).

\subsection{Biodegradation of films}

The control gelatin film (A) and nanocomposite films (B - GPCNC15; C- GCCNC15; D-GHCNC15) of size 2 x $2 \mathrm{~cm}$ weighing $99.35 \mathrm{mg}, 95.35 \mathrm{mg}, 95.74 \mathrm{mg}$ and $102.08 \mathrm{mg}$, respectively, were buried under soil and observed for a week (Fig. 9). These films were packed in a gauze cloth pocket for better aeration. The control gelatin film was completely degraded within 4 days of soil burial. The nanocomposite films were found to be crumbling, and majority of the degradation happened due to dissolution of gelatin from the films. After a week, the integrity of cellulose network was lost and the weight loss percentage of films B, C 
and $\mathrm{D}$ was found to be $61.18 \%, 71.8 \%$ and $79.9 \%$ respectively. With faster rate of biodegradation, these bio-resourced films could best suit single-use plastic application with potential environmental benefits. Similar rate of biodegradation was observed for pigskin gelatin, chitosan and sodium caseinate based composite film disintegrated under composting conditions (Bonilla \& Sobral, 2020).

\subsection{Packaging potential of films}

Single use plastic packaging elevates the plastic pollution with its short lifetime and eternal existence without degradation. Packaging applications requiring storage of products under dry, cool conditions could utilize nanocomposite films prepared in this study. The packaging potential of nanocomposite film GPCNC15 as against control gelatin film as eggplant garden seed packaging is demonstrated in Fig. 10. The garden seeds are typically packed in a plastic packaging that keeps the seed dry and viable. Viability of seeds depend on several factors including moisture content, relative humidity and temperature of storage, air permeability and quality of seeds. The GPCNC15 film was chosen based on the high UV and light blocking capability with high water contact angle. GPCNC15 packet was observed to be dry to touch when compared to gelatin films. Both control gelatin and GPCNC15 film exhibited better sealing under heat application. Despite the low transparency of the chosen nanocomposite film, the visibility of the seeds through the packaging was not much affected. In addition to the advantage of preserving the viability of the seeds for longer period, the films when discarded in soil along with the seeds could act as fertilizer due to the high protein content from the gelatin biopolymer. Biodegradation profile of GPCNC15

suggest that release of gelatin occurs within 4 days of soil burial. Thus, such strategy of packaging could benefit without any waste generation.

\section{Conclusions}

Leather waste-based gelatin composite films were prepared with cellulose II nanocrystal reinforcement at various concentrations ranging from 5 to $15 \%$. Cellulose II nanocrystal (CNC II) were isolated from wet wipe cellulose using hydrogen peroxide, citric acid and hydrochloric acid-based hydrolysis techniques and the effect of hydrolysis technique on morphological and crystalline character of the CNC was evaluated using FE-SEM, XRD and FT-IR spectroscopy. High yields of CNC II in rod like nanostructures with high crystallinity index ranging between $75.4 \%$ and $86.1 \%$ were obtained using the adopted hydrolysis techniques, within a lesser number of purification steps. PCNC and CCNC reinforcement improved the mechanical properties of gelatin films. Highly reactive and crystalline $\mathrm{CNC}$ addition imparted mechanical stiffness and strength. The thermal stability of films was improved owing to the stable cellulose II nanocrystal incorporation. The UV and Visible light barrier properties of films with PCNC were found to be maximum, enabled with the three-dimensional network formed by rod sized nanoparticle on the surface of film. Moisture sensitivities were better for films with PCNC and CCNC than with the acid hydrolyzed CNCs. Rough surface created by PCNC nanorods created hydrophobic surface on one side with water contact angle values of $98^{\circ}$. Biodegradation of nanocomposites showed that the films decompose maximum within 7 days of soil burial. Single use packaging application for eggplant garden seeds have 
been demonstrated with GPCNC15 films. Further studies are required to evaluate cost efficient production strategies and scale up capabilities of packaging films.

\section{Declarations}

\section{Acknowledgement}

Authors Vimudha Muralidharan and Saiprasad Gochhayat have equally contributed to the manuscript preparation. Vimudha Muralidharan wishes to thank the Department of Science and Technology (DST), India for providing funds through DST-INSPIRE fellowship (Grant no. DST/INSPIRE [IF170352]). Authors extend their gratitude to the CATERS department (testing facility) of CSIR-CLRI, Chennai, India, for providing the analytical services. CSIR-CLRI Communication no.: 1538

\section{Author Contribution}

Vimudha Muralidharan: Conceptualization, Methodology, Data Curation, Software, Investigating, Writing - original draft, Writing - review \& editing. Saiprasad Gochhayat: Data curation, Methodology, Investigating, Writing - review \& editing. Saravanan Palanivel: Validation, Formal analysis, Supervision, Resources. Balaraman Madhan: Supervision, Visualization, Validation, Project administration, Resources, Writing - review \& editing.

Data Availability All data generated and analyzed during this study are included in this article

Ethics approval and consent to participate Not applicable

\section{Consent for publication Consented}

Competing interests The authors declare that they have no conflict of interest in publication of this article.

\section{References}

1. Agustin MB, Ahmmad B, De Leon ERP, Buenaobra JL, Salazar JR, Hirose F (2013) Starch-based biocomposite films reinforced with cellulose nanocrystals from garlic stalks. Polym Compos 34(8):1325-1332

2. Alves JS, Reis KCD, Menezes EGT, Pereira FV, Pereira J (2015) Effect of cellulose nanocrystals and gelatin in corn starch plasticized films. Carbohydr Polym 115:215-222

3. Andonegi M, Heras KL, Vizcaino ES, Igartua M, Hernandez RM, de la Caba K, Guerrero P (2020) Structure-properties relationship of chitosan/collagen films with potential for biomedical applications. Carbohydr Polym 237:116159

4. ASTM- D1746-03 (2003) Standard test method for transparency of plastic sheeting. Annual book of American Standards testing methods. American Society for Testing \& Materials, West Conshohocken, PA, USA 
5. Beltramino F, Roncero MB, Vidal T, Torres AL, Valls C (2015) Increasing yield of nanocrystalline cellulose preparation process by a cellulase pretreatment. Biores Tech 192:574-581

6. Bonilla J, Sobral PJA (2020) Disintegrability under composting conditions of films based on gelatin, chitosan and/or sodium caseinate containing boldo-of-Chile leaf extract. Int J Biol Macromol 151:178-185

7. Briain OO, Mendes ARM, McCarron S, Healy MG, Morrison L (2020) The role of wet wipes and sanitary towels as a source of white microplastic fibres in the marine environment. Water Res 182:116021

8. Chen L, Zhu JY, Baez C, Kitin P, Elder T (2016) Highly thermal stable and functional cellulose nanocrystals and nanofibrils produced using fully recyclable organic acids. RSC Green Chemistry 18(13):3835-3843

9. Cheng M, Qin Z, Liu Y, Qin Y, Li T, Chen L, Zhu M (2014) Efficient extraction of carboxylated spherical cellulose nanocrystals with narrow size distribution through hydrolysis of lyocell fibers using ammonium persulfate as an oxidant. RSC J Mater Chem A 2:251-258

10. Chuaynukul K, Nagarajan M, Prodpran T, Benjakul S, Songtipya P, Songtipya L (2018) Comparative characterization of bovine and fish gelatin films fabricated by compression moulding and solution casting methods. J Polym Environ 26(3):1239-1252

11. Coelho CCS, Silva RBS, Carvalho CWP, Rossi AL, Teixeira JA, Silva OF, Cabral LMC (2020) Cellulose nanocrystals from grape pomace and their use for the development of starch-based nanocomposite films. Int J Biol Macromol 159:1048-1061

12. De D, Sai MSN, Aniya V, Satyavathi B (2021) Strategic biorefinery platform for green valorization of agro-industrial residues: A sustainable approach towards biodegradable plastics. J Clean Prod 290:125184

13. Du H, Liu W, Zhang M, Si C, Zhang X, Li B (2019) Cellulose nanocrystals and cellulose nanofibrils based hydrogels for biomedical applications. Carbohydr Polym 209:130-144

14. Ezati P, Riahi Z, Rhim JW (2021) Carrageenan-based functional films integrated with CuO-doped titanium nanotubes for active food packaging applications. ACS Sustainable Chemistry and Engineering 9:9300-9307

15. Fan X-M, Yu H-Y, Wang D-C, Mao Z-H, Yao J, Tam KMC (2019) Facile and green synthesis of carboxylated cellulose nanocrystals as efficient adsorbents in wastewater treatments. ACS Sustainable Chemistry and Engineering 7(21):18067-18075

16. FAO (2013) World statistical compendium for raw hides and skins. Leather and leather footwear

17. George J, Siddaramaiah (2012) High performance edible nanocomposite films containing bacterial cellulose nanocrystals. Carbohydr Polym 87:2031-2037

18. Geyer R, Jambeck JR, Law KL (2017) Production, use and fate of all plastics ever made. Sci Adv 3:15

19. Gong J, Li J, Xu J, Xiang Z, Mo L (2017) Research on cellulose nanocrystals produced from cellulose sources with various polymorphs. RSC Adv 7:33486 
20. Gonzalez-Dominguez JM, Anson-Casaos A, Grasa L, Abenia L, Salvador A, Colom E, Mesonero JE, Garcia-Bordeje JE, Benito AM, Maser WK (2019) Unique properties and behavior of non-mercerized type II cellulose nanocrystals as carbon nanotube biocompatible dispersants. Biomacromolecules 20:3147-3160

21. Haghighi H, Gullo M, China SL, Pfeifer F, Seisler HW, Licciardello F, Pulvirenti A (2021) Characterization of bio-nanocomposite films based on gelatin/polyvinyl alcohol blend reinforced with bacterial cellulose nanowhiskers for food packaging applications. Food Hydrocolloids 113:106454

22. Hosseini SF, Rezaei M, Zandi M, Farahmandghavi F (2015) Fabrication of bio-nanocomposite films based on fish gelatin reinforced with chitosan nanoparticles. Food Hydrocolloids 44:172-182

23. Huang C, Yu H, Abdalkarim SYH, Li, Chen X, Yang X, Zhou Y, Zhang L (2022) A comprehensive investigation on cellulose nanocrystals with different crystal structures from cotton via an efficient route. Carbohydr Polym 276:118766

24. Huang S, Tao R, Ismail A, Wang X (2020) Cellulose nanocrystals derived from textile waste through acid hydrolysis and oxidation as reinforcement agent of soy protein film. Polymers 12:958

25. Ji H, Xiang Z, Qi H, Han T, Pranovich A, Song T (2019) A strategy towards one step preparation of carboxylic cellulose nanocrystals and nanofibrils with high yield, carboxylation and highly stable dispersibility using innocuous citric acid. RSC Green Chemistry 21(8):1956-1964

26. Jiang F, Esker AR, Roman M (2010) Acid-catalyzed and solvolytic desulfation of $\mathrm{H}_{2} \mathrm{SO}_{4}$-hydrolyzed cellulose nanocrystals. Langmuir 26(23):17919-17925

27. Jin E, Guo J, Yang F, Zhu Y, Song J, Jin Y, Rojas OJ (2016) On the polymorphic and morphological changes of cellulose nanocrystals (CNC-I) upon mercerization and conversion to CNC-II. Carbohydr Polym 143:327-335

28. Kandasamy R, Venkatesan SK, Uddin MI, Ganesan S (2020) Anaerobic biovalorization of leather industry solid waste and production of high value-added biomolecules and biofuels. In: Biovalorisation of wastes to renewable chemicals and biofuels, pp 3-25

29. Koshani R, Van de Ven TGM, Madadlou A (2018) Characterization of carboxylated cellulose nanocrystals isolated through catalyst-assisted $\mathrm{H}_{2} \mathrm{O}_{2}$ oxidation in a one-step procedure. J Agric Food Chem 66:7692-7700

30. Lei W, Fang C, Zhou X, Yin Q, Pan S, Yang R, Liu D, Ouyang Y (2018) Cellulose nanocrystals obtained from office wastepaper and their potential application in PET packaging materials. Carbohydr Polym 181:376-385

31. Leite LSF, Moreira FKV, Mattoso LHC, Bras J (2021) Electrostatic interactions regulate the physical properties of gelatin-cellulose nanocrystals nanocomposite films intended for biodegradable packaging. Food Hydrocolloids 113:106424

32. Li W, Wang R, Liu S (2011) Nanocrystalline cellulose prepared from softwood kraft pulp via ultrasonic-assisted acid hydrolysis. BioResources 6:4271-4281 
33. Lin L, Gu Y, Cui H (2019) Moringa oil/ chitosan nanoparticles embedded gelatin nanofibers for food packaging against Listeria monocytogenes and Staphylococcus aureus on cheese. Food Packaging and Shelf Life 19:86-93

34. Liu WL, Guoying YW, Qin W (2011) Protein-based adhesive prepared from raw material of waste slag from leather making, and preparation method thereof. CN102358830A China

35. Lu Q-L, Wu J, Li Y, Huang B (2021) Isolation of thermostable cellulose II nanocrystals and their molecular bridging for electroresponsive and $\mathrm{pH}$-sensitive bio-nanocomposite. Ind Crops Prod 173:114127

36. Luchese CL, Rodrigues RB, Tessaro IC (2021) Cassava starch-processing residue utilization for packaging development. Int J Biol Macromol 183:2238-2247

37. Mahmud MM, Perveen A, Jahan RA, Matin MA, Wong SY, Li X, Arafat MT (2019) Preparation of different polymorphs of cellulose from different acid hydrolysis medium. Int $\mathrm{J}$ Biol Macromol 130:969-976

38. Mansikkamaki P, Lahtinen M, Rissanen K (2007) The conversion of cellulose I to cellulose II in $\mathrm{NaOH}$ mercerization performed in alcohol-water systems: An X-ray powder diffraction study. Carbohydr Polym 68(1):35-43

39. Masilamani D, Srinivasan V, Ramachandran KR, Gopinath A, Madhan B, Palanivel S (2017) Sustainable packaging materials from tannery trimming solid waste: A new paradigm in wealth from waste approaches. J Clean Prod 164:885-891

40. Mondragon G, Pena-Rodriguez C, Gonzalez A, Eceiza A, Arbelaiz A (2015) Bionanocomposites based on gelatin matrix and nanocellulose. Eur Polymer J 62:1-9

41. Moran JI, Alvarez VA, Cyras VP, Vazquez A (2008) Extraction of cellulose and preparation of nanocellulose from sisal fibers. Cellulose 15:149-159

42. Nagarajan KJ, Balaji AN, Rajan STK, Ramanujam NR (2020) Preparation of bio-eco based cellulose nanomaterials from used disposal paper cups through citric acid hydrolysis. Carbohydr Polym 235:115997

43. Noorbakhsh SSM, Zerafat MM, Sabbhagi S (2018) A comparative study of gelatin and starch-based nanocomposite films modified by nano-cellulose and chitosan for food packaging applications. Carbohydr Polym 189:48-55

44. Normand ML, Moriana R, Ek M (2014) Isolation and characterization of cellulose nanocrystals from sprucebark in a biorefinery perspective. Carbohydr Polym 111:979-987

45. Noshirvani N, Hong W, Ghanbarzadeh B, Fasihi H, Montazami R (2018) Study of cellulose nanocrystal doped starch-polyvinyl alcohol bionanocomposite films. Int J Biol Macromol 107:20652074

46. Pei Y, Yang J, Liu P, Xu M, Zhang X, Zhang L (2013) Fabrication, properties, and bio-applications of cellulose/collagen hydrolysate composite films. Carbohydr Polym 92:1752-1760

47. Pereira PHF, Waldron KW, Wilson DR, Cunha AP, Brito ES, Rodrigues THS, Rosa MF, Azeredo HMC (2017) Wheat straw hemicelluloses added with cellulose nanocrystals and citric acid: Effect on film 
physical properties. Carbohydr Polym 164:317-324

48. SaifulAzry SOA, Chuah TG, Paridah MT, Aung MM, Ridzuan MA, Lee CH, Sariah S, Lee SH, Juliana AH (2021) Influence of cellulose II polymorph nanowhiskers on bio-based nanocomposite film from Jatropha oil polyurethane. Mater Res Express 8:015003

49. Santos TM, Filho MM, Caceres CA, Rosa MF, Morais JPF, Pinto AMB, Azeredo HMZ (2014) Fish gelatin films as affected by cellulose whiskers and sonication. Food Hydrocolloids 41:113-118

50. Sasikala M, Umapathy MJ (2018) Preparation and characterization of pineapple leaf cellulose nanocrystal reinforced gelatin bio-nanocomposite with antibacterial banana leaf extract for application in food packaging. RSC New Journal of Chemistry 42:19979

51. Sathish M, Madhan B, Rao JR (2019) Leather solid waste: An eco-benign raw material for leather chemical preparation - A circular economy example. Waste Manage 87:357-367

52. Segal LGJMA, Creely JJ, Martin AE Jr, Conrad CM (1959) An empirical method for estimating the degree of crystallinity of native cellulose using the X-ray diffractometer. Text Res J 29:786-794

53. Uranga J, Leceta I, Extabide A, Guerrero P, de la Caba K (2016) Cross-linking of fish gelatins to develop sustainable films with enhanced properties. Eur Polymer J 78:82-90

54. Wang HY, Li DG, Yano H, Abe K (2014) Preparation of tough cellulose II nanofibers with high thermal stability from wood. Cellulose 21:1505-1515

55. Wu C-N, Saito T, Yang Q, Fukuzumi H, Isogai A (2014) Increase in water contact angle of composite film surfaces caused by the assembly of hydrophilic nanocellulose fibrils and nanoclay platelets. ACS Appl Mater Interfaces 6:12707-12712

56. Xing L, Hu C, Zhang W, Guan L, Gu J (2020) Biodegradable cellulose I (II) nanofibrils/ poly(vinyl alcohol) composite films with high mechanical properties, improved thermal stability and excellent transparency. Int J Biol Macromol 164:1766-1775

57. Xu J, Salmi J, Kloser E, Perrin F, Grosse S, Denault J, Lau PCK (2013) Feasibility of nanocrystalline cellulose production by endoglucanase treatment of natural bast fibers. Ind Crops and Prod 51:381384

58. Yang W, He X, Luzi F, Dong W, Zheng T, Kenny JM, Puglia D, Ma P (2020) Thermomechanical, antioxidant, and moisture behavior of PVA films in presence of citric acid esterified cellulose nanocrystals. Int J Biol Macromol 161:617-626

59. Yu H-Y, Zhang D-Z, Lu F-F, Yao J (2016) New approach for single step extraction of carboxylated cellulose nanocrystals for their use as adsorbents and flocculants. ACS Sustainable Chemistry and Engineering 4:2632-2643

60. Yu H, Qin Z, Liang B, Liu N, Zhou Z, Chen L (2013) Facile extraction of thermally stable cellulose nanocrystals with a high yield of $93 \%$ through hydrochloric acid hydrolysis under hydrothermal conditions. RSC J Mater Chem A 1:3938-3944

\section{Figures}



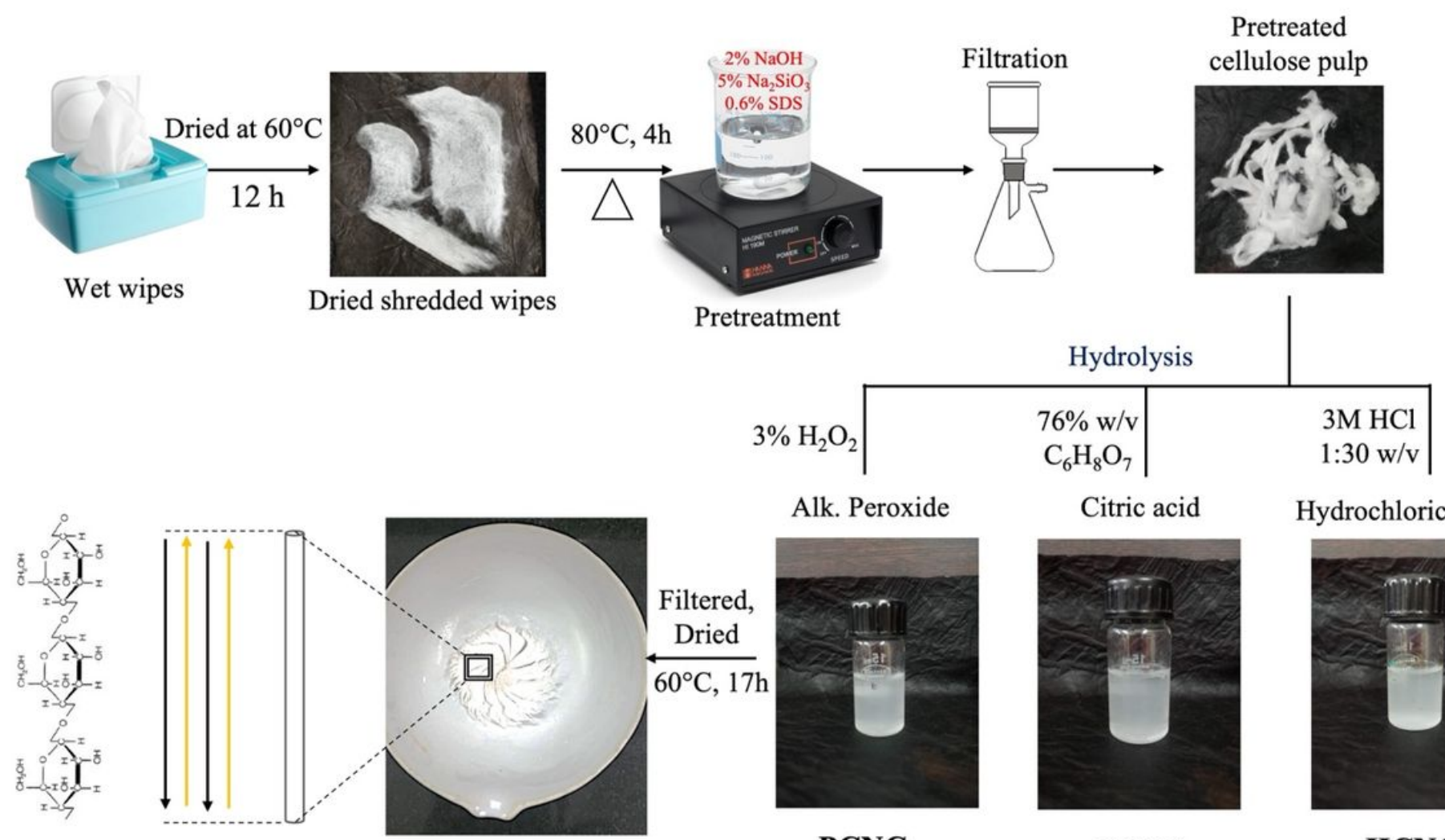

Cellulose II nanocrystal (CNC II)

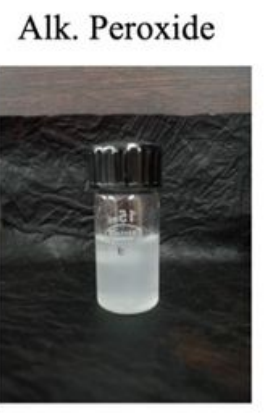

PCNC
Citric acid

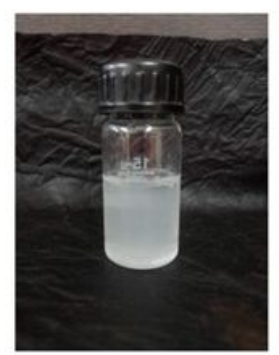

CCNC
Hydrochloric acid

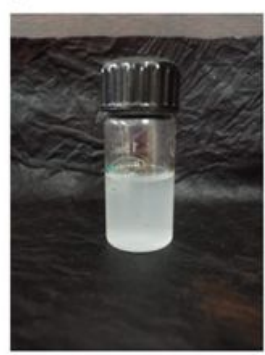

HCNC

\section{Figure 1}

Schematic illustration of cellulose II nanocrystal preparation from wet wipes

\section{Figure 2}

FE-SEM micrographs of cellulose II nanocrystals prepared by different techniques 


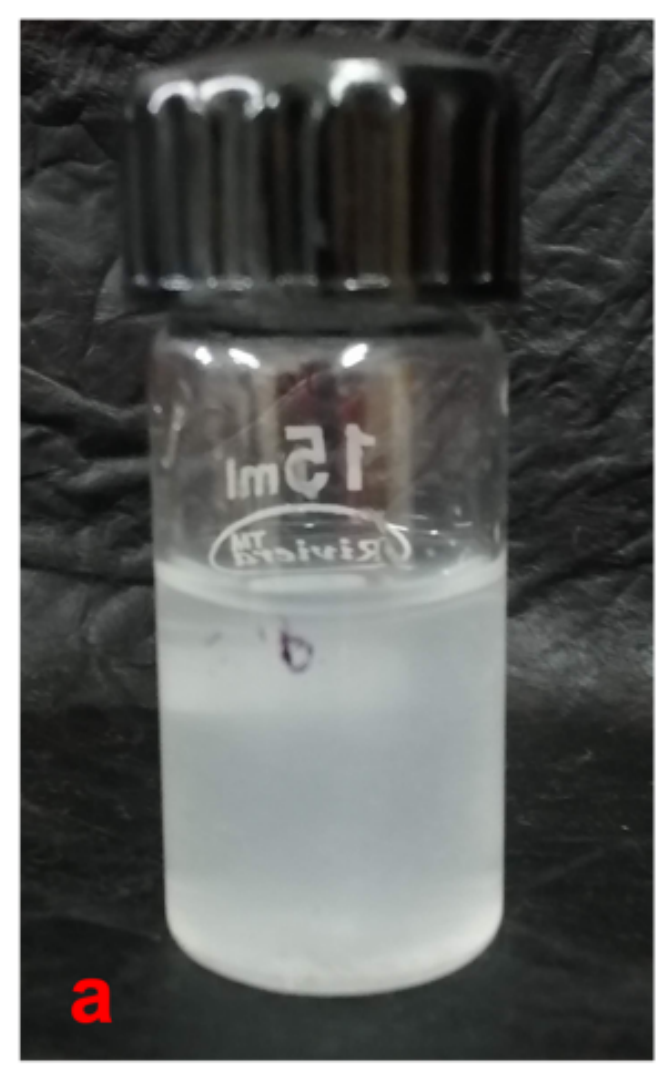

$71.13 \pm 0.6$

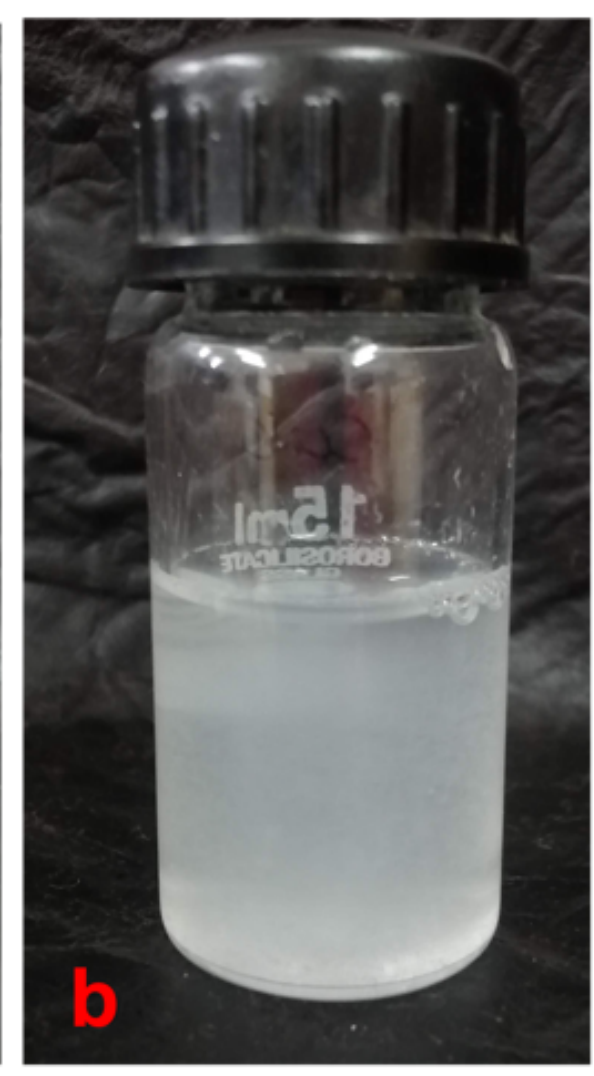

$74.06 \pm 0.2$

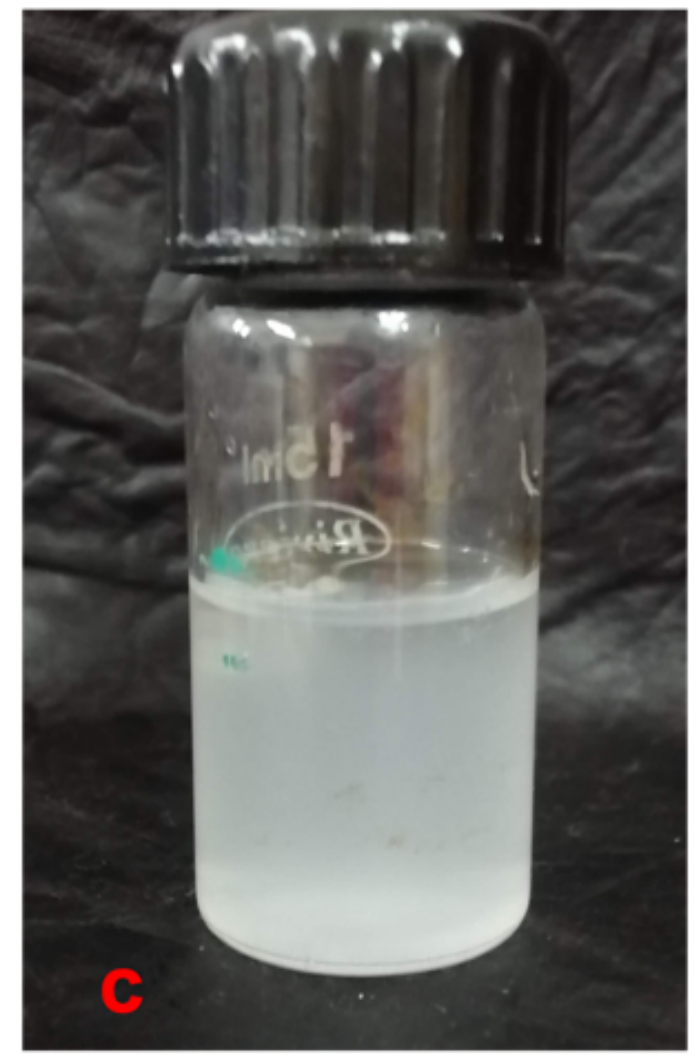

$69.5 \pm 0.4$

Figure 3

Light transmittance of CNC II suspension a) PCNC, b) CCNC, c) HCNC

Figure 4

X-Ray diffractogram of cellulose II nanocrystals

Figure 5

FTIR spectra a) CNC II and b) Gelatin-CNC films 

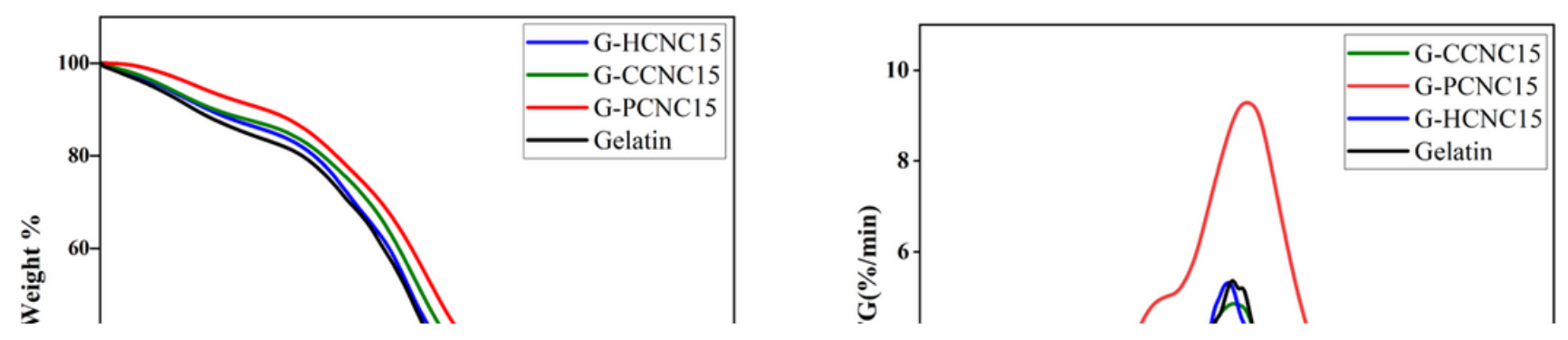

\section{Figure 6}

a) TGA, b) dTG of Gelatin-CNC films

\section{Figure 7}

DSC thermograms of nanocomposite films

\section{Figure 8}

UV-Vis Transmittance of G-CNC films

\section{Figure 9}

Visual degradation profile of nanocomposite films under soil burial degradation 
Figure 10

Packaging performance of nanocomposite films a) Control gelatin; b) GPCNC15

\section{Supplementary Files}

This is a list of supplementary files associated with this preprint. Click to download.

- floatimage1.jpeg 